\title{
Anatomical and Histological Study of Male Uropoetic Organs of Common Rabbit (Oryctolagus cuniculus)
}

\author{
Sindi Farhana*, Fathin Azhari Wibowo** \\ Undergraduate Program, Biology Education Department, Faculty of Science and Technology, UIN Sunan Kalijaga \\ Jl. Marsda Adisucipto No. 1 Yogyakarta 55281, Indonesia. Tel. + 62-274-540971, Fax. + 62-274-519739 \\ Email: sindifarhana@yahoo.com*, fath.azhari@gmail.com***
}

\begin{abstract}
Common rabbit or European rabbit (Oryctolagus cuniculus) is one of the mammals that belongs to the order Lagomorph. The study of uropoetic organs in adult male common rabbit included the anatomical and histological description at the light microscope level by using Hematoxyline and Eosine stain methods. The aims of this study was to determine the anatomical and histological features of male Oryctolagus cuniculus. Uropoetic organs of adult male common rabbit consists of four organs that is kidneys, ureters, bladder, and urethra. The result showed that Oryctolagus cuniculus have a bean-shaped kidney. The length of the right kidney is $3,4 \mathrm{~cm}$ and the width is $1,9 \mathrm{~cm}$ while the length of the left kidney is $3,2 \mathrm{~cm}$ and the width is $1,8 \mathrm{~cm}$. The histological study showed that common rabbit kidney consists of glomerulus, Bowman's capsule, proximal tubules, distal tubules, and collecting ducts.
\end{abstract}

Keywords: Anatomy, Histology, Oryctolagus cuniculus, Uropoetic organ

\section{INTRODUCTION}

Common rabbit (Oryctolagus cuniculus) belongs to the family Leporidae from order Lagomorph with the special characteristic that there is an extension of the rostrum of the skull, hairy soles to adapt to ambient temperature, and have hollowed bones to reduce body mass so that they are able to move faster to avoid predators (Pearce et al., 2007; Chapman \& Flux, 2008). Before 1912, the order Lagomorph was grouped into the order Rodent. Subsequent research shows that the anatomy of the Lagomorph is different from the Rodent because it has 6 (six) incisors, including the small incisors located behind.

The uropoetic organs are the organs that involved in mammalian urinary functions; consists of two kidney organs, two ureters that deliver urine to the urinary bladder, and urethra (Mescher, 2013). The position of the right kidney is slightly higher than the left kidney because the left kidney is pressed by the liver (Tortora \& Derrickson, 2012). In general, the normal length of the right kidney in male rabbits is about $3.15 \mathrm{~cm}$ with a width of $1.93 \mathrm{~cm}$. While the left kidney length is about $3 \mathrm{~cm}$ with a width of $1.8 \mathrm{~cm}$ (Santos-Sousa et al., 2015).

This research was conducted to study the anatomical structure and organ histology of rabbit uropoetics (Oryctolagus cuniculus).

\section{MATERIALS AND METHODS}

Adult healthy male rabbit used in this study were obtained from the local animal market. The experimental animals were anesthetized under chloroform inhalation. The skin and abdominal musculature had been dissected away to uncover the abdominal organs (Treuting \& Dintzis, 2012).

Topography of the stomach was photographed then the organs were removed and washed with $0,9 \% \mathrm{NaCl}$ solution. For histological preparation, the organs were fixed in Bouin solution for 24 hours and washed in water. Then the organs were dehydrated through ascending grades of ethanol, started from the concentration 50\% until absolute, cleared in toluene, and embeded in paraffin wax. Then the organs were sectioned at $4 \mu \mathrm{m}$ on a rotary microtome. The paraffin was removed using xylene then passed through descending grades of ethanol. To conduct histological studies, sections were stained with hematoxylin and eosin (H\&E). The tissue sections were cleared using xylene and mounted as per usual methods (Bancroft et al., 2012). Section were examined using Nikon light microscope equiped with an OptiLab camera.

\section{RESULTS AND DISCUSSION}

Description of Macroscopic Anatomy of Male Oryctolagus cuniculus Uropoetic Organs

Uropoetic organs is organs that involved in urinary system, consists of a pair of kidneys, ureters, urinary bladder, and urethra.

Kidneys of $O$. cuniculus species have a dark red color and bean-shaped, located retroperitoneally (Figure 1) (Ross et al., 2003). The right kidney is higher than the left kidney, countering the human kidney which the right is lower than the left. This is because the liver occupies considerable space on the left side superior to the kidney (Tortora \& Derrickson, 2012). The ureter connects each kidney to urinary bladder, then the urinary bladder connected to urethra. 
Ureters is a The urethra in male rabbit is located inside the penis (Figure 2).

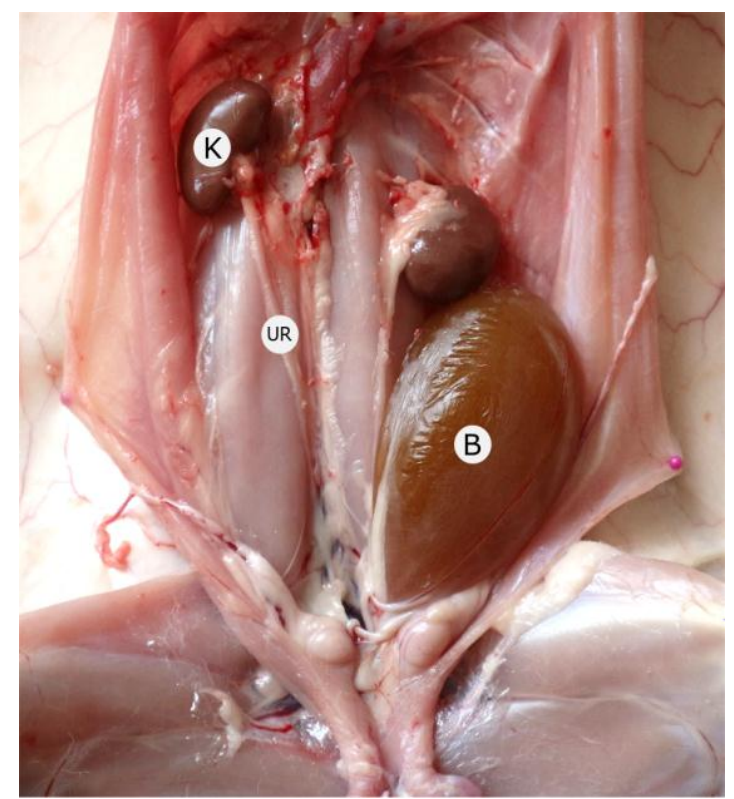

Figure 1. Anatomy of uropoetic organs of common rabbit that consist of kidneys $(\mathrm{K})$ that located between peritoneum and posterior wall of abdomen, a pair of ureter (UR), urinary bladder (B) that located above the rectum.

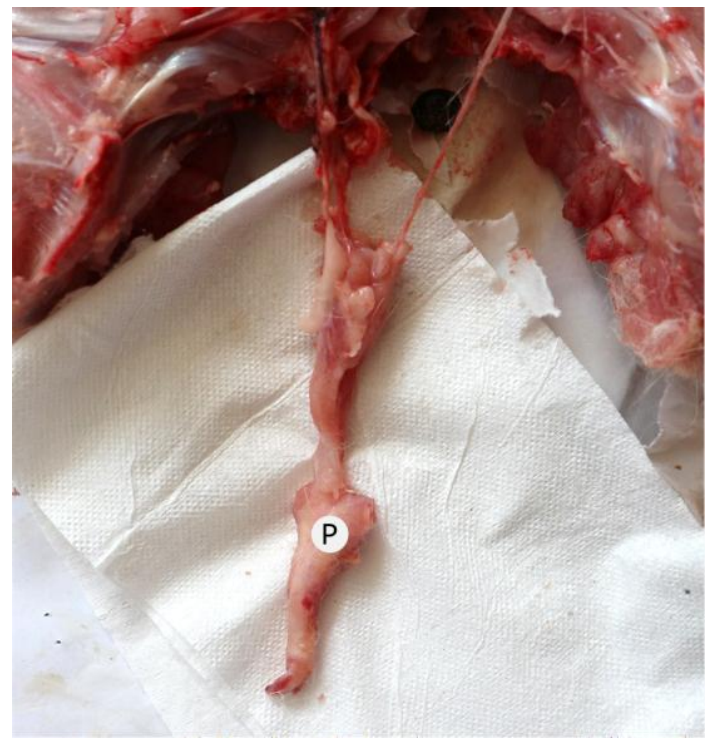

Figure 2. Uropoetic organs also consist of uretra that located inside the Penis $(\mathrm{P})$.

\section{Description of Histology of Male Oryctolagus cuniculus Uropoetic Organs}

Histological character of male $O$. cuniculus are not much different from other mammals. Generally, the kidneys have osmoregulator function by regulate the blood compotition in optimum amount (Kent, 1987; Mescher, 2013). Kidneys of O. cuniculus mainly consist of two parts in sagittal region i.e. cortex and medulla. Cortex is the outer part of the kidney that stained darker and inner part called medulla that stained lighter (Figure 3). Externally, the cortex is covered with a dense, irregular connective tissue called renal capsule (Figure 4). Renal capsule composed by fibrose and elastic fibers and a bit of smooth muscles (Eroschenko, 2005).

The higher magnification of cortex shows proximal and distal tubules, glomerulus, and medulla rays. Medulla rays consist of nephron that ordered straightly, blood vessels, and collective tubules that connected to medulla forming collective duct (Eroschenko, 2005).

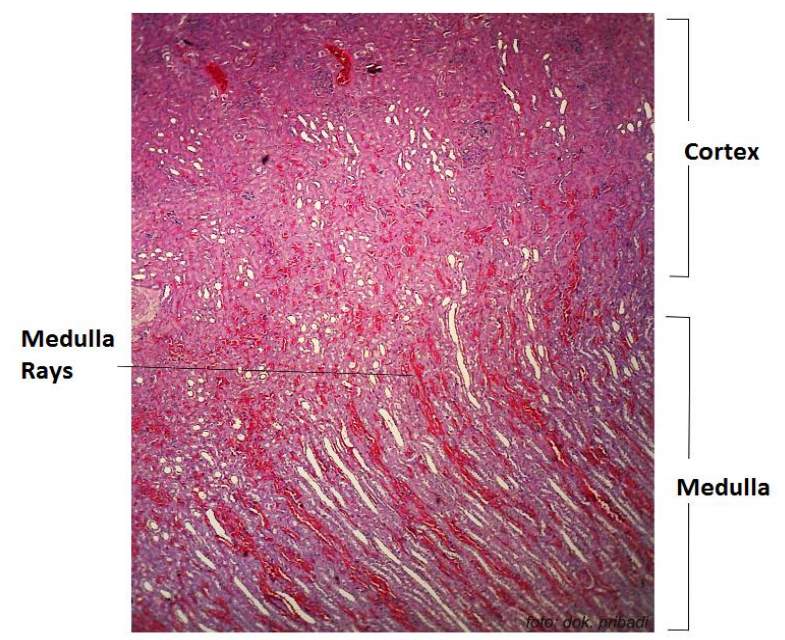

Figure 3. Histology of kidney cortex and upper medulla. Stained in Hematoxylin and Eosin. Magnification 100x.

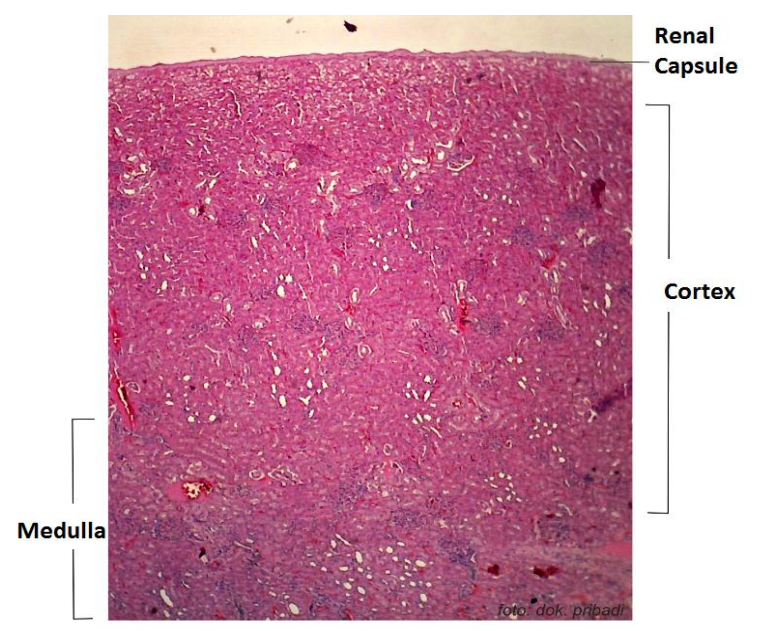

Figure 4. Histology of cortex and medulla with renal capsule. Stained in Hematoxylin and Eosin. Magnification 40x.

Each kidney have millions of microscopic uriniferous tubules that consist of nephron and collective duct. The nephron is subdivided to renal corpuscle and renal tubules. Part of renal corpuscle is glomerulus that showed in Figure 5. While the higher magnification of nephron showed afferent arteriole, glomerulus, Bowman's capsule, proximal tubules, and distal tubules (Figure 6). 
About $21 \%$ of blood were pumped by heart throughout the kidney. Blood from the body that entered renal artery will pass through afferent arteriole to glomerulus. Inside the glomerulus, there will occur filtration process. Unspecific filtration occur at the filtration process where the component that pass through glomerulus based on the size and mass of the molecules. The component that can pass through it i.e. water and most of other substance, unless plasma protein, blood cells, and platelets. The product of the filtration called glomerulus filtrate that will flow through Bowman's capsule toward proximal tubules (Eroschenko, 2005).

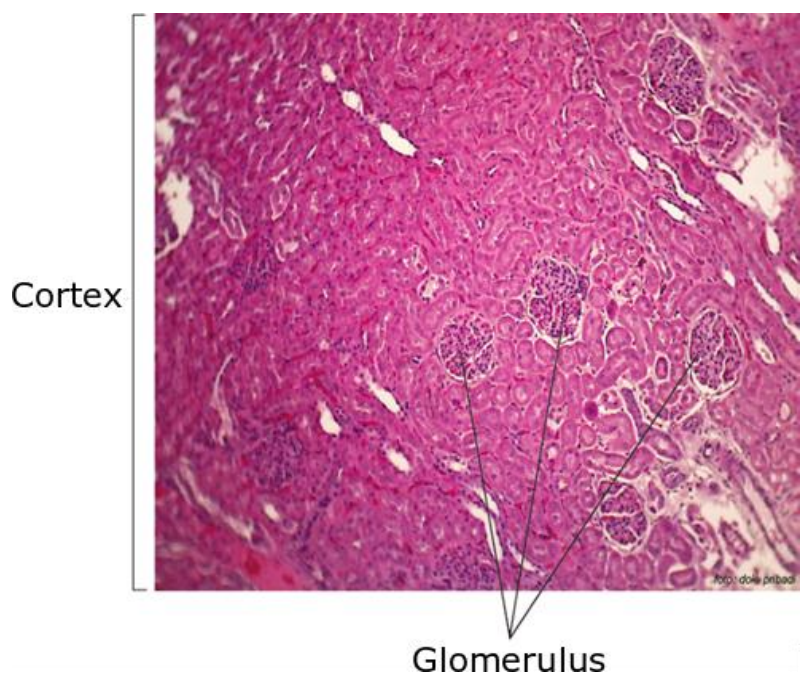

Figure 5. Histology of kidney cortex in 100x magnification shows a part of renal corpuscle that is glomerulus. Stained in Hematoxylin and Eosin.

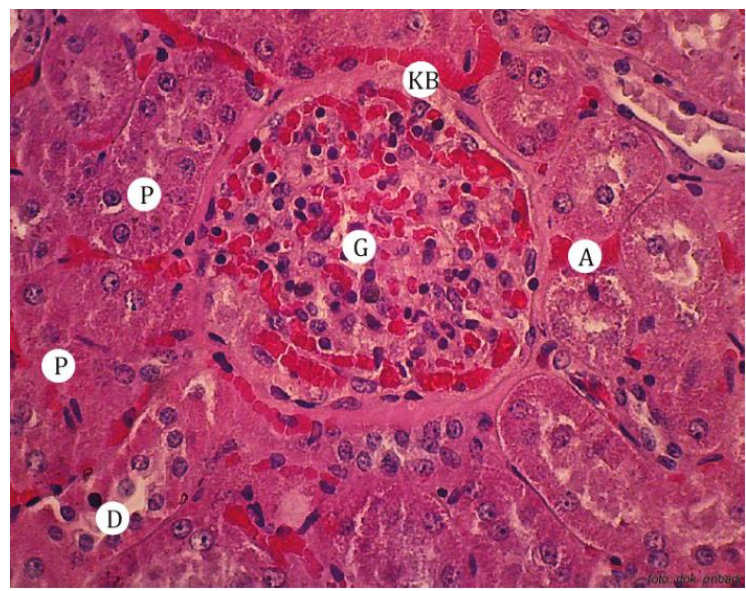

Figure 6. Histology of nephron in 400x magnification shows afferent arteriole (A), Glomerulus (G), Bowman's capsule (KB), Proximal tubules (P), and Distal tubules (D).

Components soluted in glomerulus filtrate that still needed will be reabsorbed by promixal tubules back to blood stream. Afterwards, the filtrate will undergo augmentation process in the end of distal tubules. The product of this process will flow from distal tubules to collective tubules (Eroschenko, 2005). The collective tubules showed in the high magnification of cortex (Figure 7). Collective tubules that merged each other will form collective duct. The high magnification of medulla shows the collective duct (Figure 8).

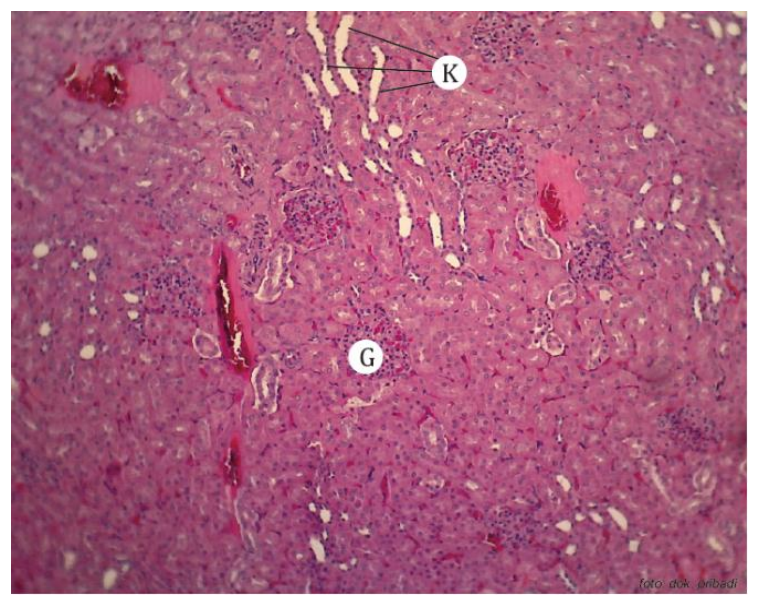

Figure 7. Histology of cortex that shows Glomerulus (G) and Collective tubules (K). Magnification 100x. Stained in Hematoxylin and Eosin.

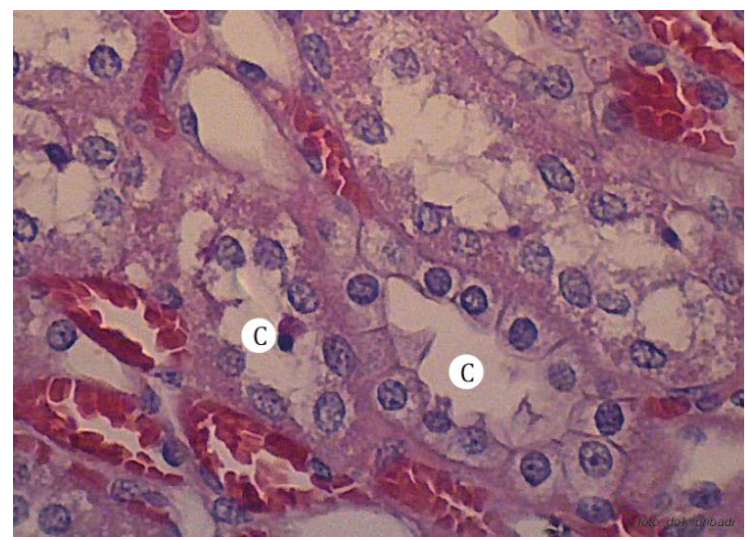

Figure 8. Histology of medulla that shows Collective duct (C). Magnification 400x. Stained in Hematoxylin and Eosin.

The urine from the kidneys will flow through the ureter to the urinary bladder for temporary storage before being released through the urethra. Peristaltic contraction that occurs in the muscular wall of the ureter push urine into the urinary bladder. In addition, hydrostatic pressure and gravity also push urine from the ureter into the urinary bladder. The ureter and urinary bladder have the same histological structure. The mucosa of these organs is lined by a unique layered transitional epithelium or urothelium. The epithelium is surrounded by the folded lamina propria and submucosa, followed by the muscular layer in the form of smooth muscle, also followed by tunica adventitia that mixed with adipose tissue (Figure 9).

The urinary bladder is a hollowed organ that has a thick muscle wall. The main function of this organ is as 
a temporary storage for urine. Because the lumen of the urinary bladder is surrounded by a transitional epithelium, the urinary bladder wall can widen when filled with urine. When the urinary bladder is empty, there will be a layer of connective tissue and smooth muscle (Figure 10).

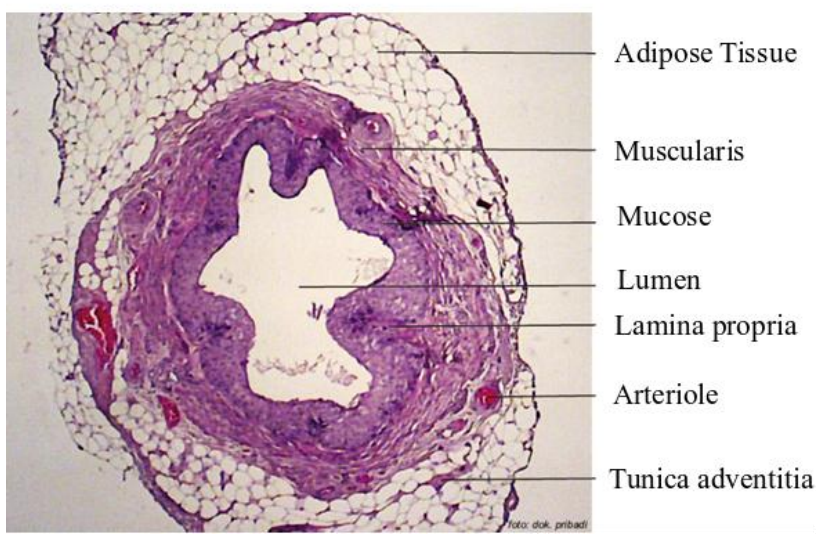

Figure 9. Transverse section of ureter in 40x magnification. Stained in Hematoxylin and Eosin.

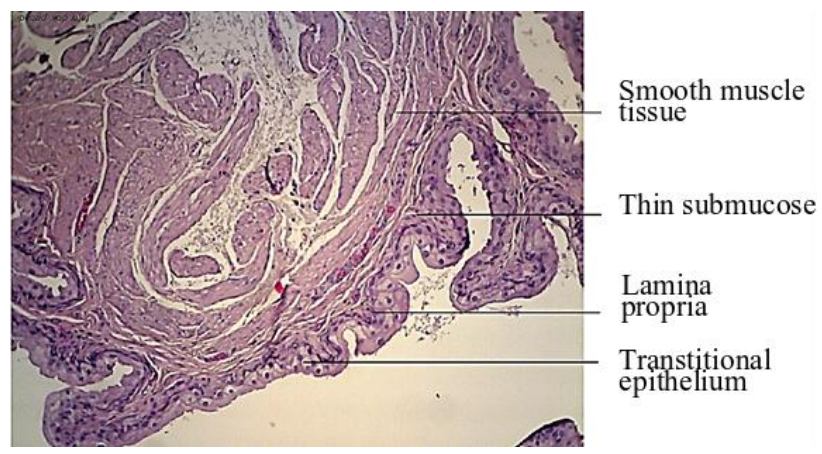

Figure 10. Histology of urinary bladder in 100x magnification. Stained in Hematoxylin and Eosin.

When the urinary bladder is filled with urine, urine must be removed from the body through the urethra. The urethra is a fibromuscular channel located at the tip of the urinary bladder to the outer surface of the body. In males, at the same time the urethra is the channel that carries semen (containing sperm cells). The urethral canal is composed of layers of mucosal tissue and muscularis tissue (Figure 11).

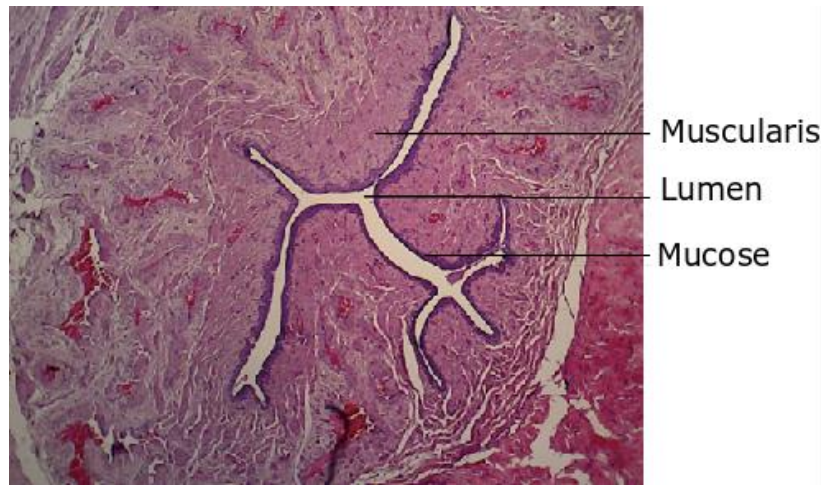

Figure 11. Histology of urethra that located in the medial region of penis in 40x magnification. Stained in Hematoxylin and Eosin.

\section{CONCLUSIONS}

Species of common rabbit (Oryctolagus cuniculus) uropoetic organs consists of a pair of kidneys, ureter, bladder, and urethra. The histology of the four organs have similar histological structure to other mammal in general.

\section{REFERENCES}

Bancroft, J.D., Suvarna, K., Layton, C. 2012. Bancroft's Theory and Practice of Histological Techniques 7th Ed. Edinburgh: The Churchill Livingstone.

Chapman, JA. \& Flux, JEC. 2008. "Introduction to the Lagomorpha" dalam P.C. Alves, N. Ferrand, \& K. Hackländer (Eds.) Lagomorph Biology: Evolution, Ecology, and Conservation. Berlin: Springer.

Eroschenko, Victor P. 2005. diFiore's Atlas of Histology with Functional Correlations. USA: Lippincott Williams and Wilkins.

Kent, George C. 1987. Comparative Anatomy of the Vertebrates. USA: Mosby.

Mescher, Antony L. 2013. Junquire's Basic Histology Text \& Atlas. USA: McGraw Hill.

Pearce, AI., Richards, RG., Milz, S., Schneider, E., Pearce, SG. 2007. Animal Models for Implant Biomaterial Research in Bone: a review. European Science and Materials Journal. 13: 110.

Ross M., Kaye GI., Pawlina W. 2003. Histology a Text and Atlas with Cell and Molecular Biology. USA: Lippincott William \& Wilkins.

Santos-Sousa, CA., Stocco, AV., Mencalha, R., Jorge, SF., AbiduFigueiredo, M. 2015. Morphometry and Vascularization of the Rabbit Kidneys (Oryctolagus cuniculus). International Journal of Morphology. 33(4): 1293-1298.

Tortora, GJ. \& Derrickson, B. 2012. Principles of Anatomy \& Physiology 13th Edition. USA: John Wiley \& Sons, Inc.

Treuting, P.M. and Dintzis, S.M. 2012. Comparative Anatomy and Histology 1st Ed. USA: Elsevier. 